\title{
Disruption of Mesolimbic Regulation of Prefrontal Cholinergic Transmission in an Animal Model of Schizophrenia and Normalization by Chronic Clozapine Treatment
}

\author{
Kathleen S Alexander', Julie M Brooks', Martin Sarter² and John P Bruno*,' \\ 'Department of Psychology, The Ohio State University, Columbus, OH, USA; '2Department of Psychology, University of Michigan, Ann Arbor, MI, USA
}

\begin{abstract}
Abnormal mesolimbic control of cortical cholinergic activity has been hypothesized to contribute to the cognitive symptoms of schizophrenia. Stimulation of NMDA receptors in nucleus accumbens (NAC) increases acetylcholine (ACh) release in prefrontal cortex (PFC), an activation thought to contribute to attentional processing. Thus, the effects of intra-NAC perfusion of NMDA (250-400 $\mu$ M)

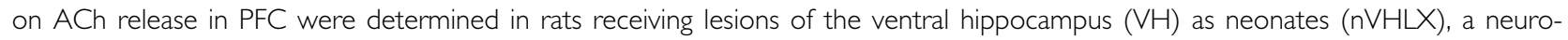
developmental model of schizophrenia, or as adults (aVHLX). NMDA elevated ACh release (I00-150\% above baseline) in adults sham-lesioned as neonates or in aVHLX rats. Adult $\mathrm{nVHLX}$ were unresponsive to NAC NMDA receptor stimulation. The inability of $\mathrm{nVHLX}$ to respond to NMDA emerged over development as a separate experiment demonstrated that evoked ACh release was normal before puberty (100-150\% increase) yet, in these same $\mathrm{nVHLX}$ animals, absent after puberty. Amphetamine-evoked ACh release was assessed in $\mathrm{nVHLX}$ animals to exclude potential limitations in release capacity. Amphetamine produced greater increases in ACh release than in shams, indicating that $\mathrm{nVHLX}$ does not impair the capacity of cholinergic neurons to release ACh. Finally, the ability of 13 days of pretreatment with clozapine ( $1.25 \mathrm{mg} / \mathrm{kg} / \mathrm{day})$ to reinstate NMDA-evoked cortical ACh efflux was determined. Clozapine treatment normalized NMDA-evoked ACh release in $\mathrm{nVHLX}$ animals. These experiments show that mesolimbic regulation of cortical ACh release is disrupted in postpubertal $\mathrm{nVHLX}$ rats and normalized by low-dose treatment of clozapine; supporting the usefulness of $\mathrm{nVHLX}$ animals for research on the neuronal mechanisms underlying the cognitive symptoms of schizophrenia. Neuropsychopharmacology (2009) 34, 2710-2720; doi:10.1038/npp.2009.105; published online 19 August 2009
\end{abstract}

Keywords: acetylcholine; hippocampus; prefrontal cortex; nucleus accumbens; schizophrenia; clozapine

\section{INTRODUCTION}

Persistent cognitive impairments have been increasingly considered a major hindrance for patients with schizophrenia to return to a productive life. The NIMH-sponsored initiatives MATRICS and CNTRICS (Kerns et al, 2008; Barch et al, 2009) assisted in bringing this issue back to the forefront, focused the attention of researchers on specific cognitive domains and tasks and, importantly, emphasized the importance of developing more animal models of these impairments that are broadly valid and useful (Hagan and Jones 2005; Nuechterlein et al, 2004).

Since the original descriptions by Kraepelin, impairments in attention have been considered a central and perhaps even fundamental component of the cognitive symptoms of schizophrenia (for review see Nuechterlein and Dawson 1984; Braff and Light 2004). As cortical cholinergic

*Correspondence: Dr JP Bruno, Department of Psychology, Ohio State University, 57 Psychology Bldg, 1835 Neil Ave, Columbus, OH 43210 , USA, Tel: + | 614292 1770, Fax: + I 614688 4733,

E-mail: bruno.1@osu.edu

Received I0 June 2009; revised I5 July 2009; accepted I6 July 2009 neurotransmission has been extensively shown to be necessary for the mediation of attentional performance (for review see Sarter et al, 2005a), we hypothesized that a dysregulated cortical cholinergic input system is an integral component of the forebrain circuitry responsible for mediating the persistent cognitive impairments of schizophrenia (for review see Sarter et al, 2005b). Although evidence indicating abnormal cholinergic neurotransmission in schizophrenia has been accumulating (Hyde and Crook 2001; Raedler et al, 2003), it has remained difficult to determine the presumably dynamic characteristics of such dysregulation in humans based on postmortem analyses, thus presently limiting this research mostly to studies using animal models (Kozak et al, 2007; Sarter et al, 2009).

Research in intact animals has shown a critical role for a distributed, interconnected neural system consisting mainly of the prefrontal cortex (PFC), nucleus accumbens (NAC), and the area in the basal forebrain from which the forebrain cholinergic system originates (BFCS), in the regulation of cortical acetylcholine (ACh) release (Brooks et al, 2007; Zmarowski et al, 2005) and the mediation of attention (Sarter et al, 2005a,b; Himmelheber et al, 2000; Kozak et al, 2006). Specifically, we found that activation of NAC NMDA 
receptors stimulates ACh release in PFC (Brooks et al, 2007; Zmarowski et al, 2005). Moreover, this evoked release was evident in prefrontal but not in posterior parietal cortex (Zmarowski et al, 2007). Effective attentional processing, including the motivated maintenance or recovery of attentional performance after performance-taxing events (such as distractors), involves the mesolimbic recruitment of the BFCS (Sarter et al, 2006). This is of relevance for understanding the neuronal mechanisms mediating the attentional impairments in schizophrenics because during periods of remission, such impairments are robustly evoked by performance-taxing demands (reviewed in Sarter et al, 2009). Thus, the present experiment assessed this interplay between the NAC and PFC ACh release in an animal model of schizophrenia.

In this study, we chose to focus on the model of damage to the developing ventral hippocampus ( $\mathrm{VH}$; Lipska et al, 1993; O'Donnell et al, 2002) because (a) projections from $\mathrm{VH}$ have been shown to influence the operations of the PFC (Bhardwaj et al, 2003; Lipska et al, 2003; Tseng et al, 2006) and (b) hippocampal efferents have an important function in gating the responsiveness of NAC neurons to prefrontal inputs (O'Donnell and Grace 1995; Goto and O'Donnell 2002). Furthermore, neonatal lesions of the VH (nVHLX) result in abnormal dopamine-glutamate/GABA interactions in the PFC (Tseng et al, 2007; Tseng et al, 2008). Although the determination of the attentional capacities of nVHLX animals requires more research, the available evidence indicates that such impairments are present (Marquis et al, 2008). Thus, nVHLX animals model the abnormal prefrontal-mesolimbic interactions that are generally hypothesized to represent a core component of the disease. We hypothesized that these abnormal interactions also include the BFCS and prefrontal cholinergic inputs. The evidence described below confirms that the mesolimbic regulation of PFC ACh release is fundamentally disrupted in nVHLX animals, further supporting the usefulness of this model for studying the neuronal mechanisms responsible for the cognitive symptoms of schizophrenia.

\section{MATERIALS AND METHODS}

\section{Animals}

Male Wistar rats (Charles River, Wilmington, MA, USA) were used. Neonatal rats were bred in our colony and were weaned on postnatal day (PND) 21. Animals were maintained on a $12: 12 \mathrm{~h}$ light/dark cycle (lights on $0600 \mathrm{~h}$ ) in a temperature- and humidity-controlled AAALAC-approved animal facility. Animals were individually housed in plastic cages lined with corn cob bedding (Harlan Teklad, Madison, WI, USA) with ad libitum access to food and water. All procedures were approved by The Ohio State University Institutional Animal Care and Use Committee in accordance with the NIH Guide for the Care and Use of Laboratory Animals.

\section{Neonatal Ventral Hippocampal Lesions (nVHLX)}

Neonatal surgery was performed when pups weighed 15-20 g ( PND 7-9). Pups were anesthetized by hypothermia until they were immobile. The ventral hippocampal lesion was made by penetrating the skull with an infusion syringe ( $10 \mu \mathrm{l}$ syringe, $26 \mathrm{G}$ needle) at coordinates AP $-3.0 \mathrm{~mm}, \mathrm{ML} \pm 3.5 \mathrm{~mm}, \mathrm{DV}-5.0 \mathrm{~mm}$ relative to Bregma. Ibotenic acid (Sigma-Aldrich, St Louis, MO; $10 \mu \mathrm{M}$ ) was then infused into the $\mathrm{VH}$ at a rate of $0.15 \mu \mathrm{l} / \mathrm{min}$ for a total of $0.3 \mu \mathrm{l}$. After the infusion was complete, the needle was left in place for an additional $3 \mathrm{~min}$ to allow diffusion of the excitotoxin and prevent backflow up the needle tract. This procedure was then repeated in the contralateral hemisphere. For sham surgery, $0.3 \mu \mathrm{l}$ of artificial cerebrospinal fluid (aCSF, see below) was infused at the same rate. After surgery, the pups were warmed on a heating pad and returned as a group to the litter's nest area. Pups and dams were left undisturbed until weaning on PND 21.

\section{Adult Ventral Hippocampal Lesions (aVHLX)}

Adult male Wistar rats (PND 64-75 at the time of lesion) were used. Animals were anesthetized with inhalant isofluorane $\left(2 \%, 0.6 \mathrm{l} / \mathrm{min}, \mathrm{O}_{2}\right)$ and $0.3 \mu \mathrm{l}$ ibotenic acid $(10 \mu \mathrm{M})$ was bilaterally infused (two locations/hemisphere) into the $\mathrm{VH}$ at a rate of $0.15 \mu \mathrm{l} / \mathrm{min}$ at the following coordinates (in $\mathrm{mm}$ from Bregma): $\mathrm{AP}-4.4, \mathrm{ML} \pm 5.0$, DV -6.0 , and $\mathrm{AP}-4.4, \mathrm{ML} \pm 5.0, \mathrm{DV}-8.0$. After each infusion, the needle remained in place for $3 \mathrm{~min}$ before being removed. After surgery, the animals were returned to their home cages and left undisturbed for 28 days.

\section{Guide Cannula Implantation}

Animals to be tested prepuberty were implanted with microdialysis guide cannula on approximately PND 30 . Animals were anesthetized using isoflurane. Rats were implanted unilaterally with stainless steel guide cannulae (SciPro Inc, Sanborn, NY, USA) in the mPFC and the NAC. The mPFC guide cannula $(0.38 \mathrm{~mm}$ o.d., $15 \mathrm{~mm}$ shaft $)$ was implanted at a $20^{\circ}$ rostral angle at AP: $+4.2, \mathrm{ML}: \pm 0.6, \mathrm{DV}$ : $-0.6 \mathrm{~mm}$ relative to Bregma. The NAC cannula $(0.38 \mathrm{~mm}$ o.d., $20 \mathrm{~mm}$ shaft) was implanted at a $0^{\circ}$ (ie vertical) angle at $\mathrm{AP}:+1.5, \mathrm{ML} \pm 0.8, \mathrm{DV}-5.6 \mathrm{~mm}$ relative to Bregma. Cannulae were fixed to the skull using skull screws and dental cement. To prevent clogging of the cannulae shafts, stylets ending flush with the guide cannulae were inserted. Antibiotic ointment (Neosporin) was applied to the area around the incision, and the animals were returned to their home cages.

Animals to be tested post puberty were cannulated between PND 56 and 70. Surgical procedures and cannula angles were the same as those described for prepuberty cannulation, with the following coordinates: $\mathrm{PFC}, \mathrm{AP}+4.2$, $\mathrm{ML} \pm 0.6, \quad \mathrm{DV}-0.6 \mathrm{~mm} ; \mathrm{NAC}, \mathrm{AP}+1.3, \mathrm{ML} \pm 1.0, \mathrm{DV}$ $-5.8 \mathrm{~mm}$ relative to Bregma.

\section{General Microdialysis Procedures}

The effects of NAC infusions, amphetamine, or clozapine, and their respective vehicles, were all tested as withinsubjects variables and with counterbalanced order of drug and vehicle. Animals had at least 1 day between two successive microdialysis sessions. During a standard microdialysis session, animals were allowed to habituate to the test chamber (microdialysis bowl: diameter $=39 \mathrm{~cm}$, 
height $=32 \mathrm{~cm}$, Carnegie Medicine, Stockholm, Sweden) for $15 \mathrm{~min}$, after which concentric dialysis probes (mPFC: $0.2 \mathrm{~mm}$ o.d., $3.0 \mathrm{~mm}$ membrane tip; NAC: $0.2 \mathrm{~mm}$ o.d., $2.0 \mathrm{~mm}$ membrane tip; SciPro Inc) were inserted into the guide cannulae. Animals were then perfused with aCSF $[\mathrm{NaCl}$ $(126.5 \mathrm{mM}), \mathrm{NaHCO}_{3}(27.5 \mathrm{mM}), \mathrm{KCl}(2.4 \mathrm{mM}), \mathrm{Na}_{2} \mathrm{SO}_{4}$ $(0.5 \mathrm{mM}), \quad \mathrm{KH}_{2} \mathrm{PO}_{4} \quad(0.5 \mathrm{mM}), \quad \mathrm{CaCl}_{2} \quad(1.1 \mathrm{mM}), \quad \mathrm{MgCl}_{2}$ $(0.8 \mathrm{mM})$, dextrose $(1 \mathrm{mM})]$, at a $1.25-2.0 \mu \mathrm{l} / \mathrm{min}$ flow rate. The perfusion medium did not include an acetylcholinesterase inhibitor. After probe insertion, a $3 \mathrm{~h}$ washout period was observed to allow for stable levels of basal ACh release. After this washout period, four baseline collections were taken in $15 \mathrm{~min}$ intervals. After baseline collections, drugs were perfused into the NAC over the course of $1 \mathrm{~h}$, during which four collections were taken. After drug perfusion, aCSF was once again perfused through the NAC probe and three additional collections were taken to determine whether ACh returned to basal levels. Immediately after session completion, probes were removed from the cannulae and stylets were replaced in the cannulae. Animals were then returned to their home cages. Between dialysis sessions, each dialysis probe was stored in an antibacterial agent (ProClin 150 Reagent, BAS Inc, W. Lafeyette, IN, USA) to ensure sterility.

\section{Specific Microdialysis Procedures for Individual Experiments}

Experiment 1a: animals lesioned as neonates and tested as adults. Animals sustaining ventral hippocampal lesions as neonates (nVHLX) and their sham controls were tested as adults in two $7 \mathrm{~h}$ dialysis sessions as described in 'General Microdialysis', consisting of intra-NAC perfusion of aCSF or NMDA $(400 \mu \mathrm{M})$ in counterbalanced order (see figure legends for number of animals per group). This concentration of NMDA was the higher concentration tested in Zmarowski et al (2007) and although not producing greater cortical ACh release than the lower concentration $(250 \mu \mathrm{M})$ was selected for Experiment 1a to minimize a potential false-negative finding. As this higher concentration did not evoke PFC ACh release in nVHLX animals, subsequent experiments were conducted with the lower concentration, in part, to minimize nonselective effects (see Zmarowski et al, 2005, 2007).

Experiment 1b: animals lesioned as adults and tested as adults. Animals sustaining ventral hippocampal lesions as adults (aVHLX) and their sham controls were tested as adults in two $7 \mathrm{~h}$ sessions as described in 'General Microdialysis', consisting of intra-NAC perfusion of aCSF or NMDA $(250 \mu \mathrm{M})$ in counterbalanced order.

Experiment 2: animals lesioned as neonates and tested before and after puberty. nVHLX rats and their sham controls were tested in five, $7 \mathrm{~h}$ sessions, as described in 'General Microdialysis'. Each animal received two dialysis sessions before puberty (PND 30-38) and three sessions after puberty (PND 56-64). The prepuberty sessions included aCSF or NMDA $(250 \mu \mathrm{M})$ perfused into the NAC in counterbalanced order. The postpuberty sessions included aCSF, NMDA $(250 \mu \mathrm{M})$, or systemic amphetamine (AMPH, $2 \mathrm{mg} / \mathrm{kg}$, i.p.) presented in counterbalanced order.
Experiment 3: treatment with clozapine. At PND 58, nVHLX and their sham controls were randomly divided into two drug pretreatment groups. Animals received once daily injections (i.p.) of either clozapine $(1.25 \mathrm{mg} / \mathrm{kg}, \mathrm{pH}=7.4$, Sigma-Aldridge, St. Louis, MO) or saline. The selection of clozapine dose was guided by several observations. First, studies in schizophrenic patients showed moderately beneficial cognitive effects after low-dose treatment with first- and second-generation antipsychotics (see Mishara and Goldberg, 2004 for a meta-analysis). Second, we have shown that lowdose treatment of clozapine $(2.5 \mathrm{mg} / \mathrm{kg})$ in rats, defined in terms of 50\% D2 receptor occupation (Kapur et al, 2003), enhances the attentional performance of rats in a different model of schizophrenia (Martinez and Sarter, 2008; Rueter et al, 2004). Third, as we and others (Ichikawa et al, 2002; Li et al, 2005) observed that doses higher than $1.25 \mathrm{mg} / \mathrm{kg}$ increased basal cortical ACh release (an effect that would have confounded this experiment), we further reduced the dose to $1.25 \mathrm{mg} / \mathrm{kg}$. Injections continued for 13 days with guide cannulae implantation surgery occurring on injection day 7 . Microdialysis testing occurred on days 11 and 13 of drug treatment injection regimen with injections given immediately before dialysis probe insertion. Dialysis sessions for this experimental group were identical to those described in 'Experiment 1' with each subject receiving, in counterbalanced order, aCSF or NMDA $(250 \mu \mathrm{M})$ during drug perfusion collections.

\section{ACh Quantification}

ACh samples were stored $\left(-80^{\circ} \mathrm{C}\right)$ until analyzed using high performance liquid chromatography with electrochemical detection. Using an autosampler (ESA Inc, Chelmsford, MA), $15 \mu$ l of each sample was injected through a UniJet microbore analytical column $(1 \mathrm{~mm} \times 50 \mathrm{~mm}$, BAS Inc) using a sodium phosphate mobile phase $\left(35 \mathrm{mM} \mathrm{Na}_{2} \mathrm{HPO}_{4}\right.$, $483.55 \mu \mathrm{M}$ EDTA, $0.005 \%$ microbicide reagent ProClin, $\mathrm{pH}=8.5$; flow rate of $0.15 \mathrm{ml} / \mathrm{min}$ ) to separate $\mathrm{ACh}$ and choline. The sensitivity of the ACh assay was enhanced by using a precolumn immobilized enzyme reactor (IMER; BAS Inc), containing choline oxidase and catalase, to oxidize extracellular choline. After separation of $\mathrm{ACh}$, a postcolumn enzyme reactor (BAS Inc) was used to convert ACh into the reporting molecule $\mathrm{H}_{2} \mathrm{O}_{2}$ (Potter et al, 1983). $\mathrm{H}_{2} \mathrm{O}_{2}$ was quantified with a peroxidase-wired glassy carbon electrode (Model no. 5041 analytical cell, ESA Inc) with an applied potential of $-200 \mathrm{mV}$ (Huang et al, 1995).

\section{Histological Procedures}

At the end of each experiment, animals were deeply anesthetized with sodium pentobarbital $(100 \mathrm{mg} / \mathrm{kg}$, i.p.) and intracardially perfused, first with heparinized saline and then with formalin. The brains were extracted, prepared with a $30 \%$ sucrose solution, frozen, sliced with a cryostat, mounted on microscope slides, and stained with cresyl violet for verification of cannulae placements and extent of lesion.

\section{Statistical Analyses}

In each experiment, baseline (collections 1-4) values of extracellular $\mathrm{ACh}(\mathrm{fmol} / 15 \mu \mathrm{l})$ were compared using 

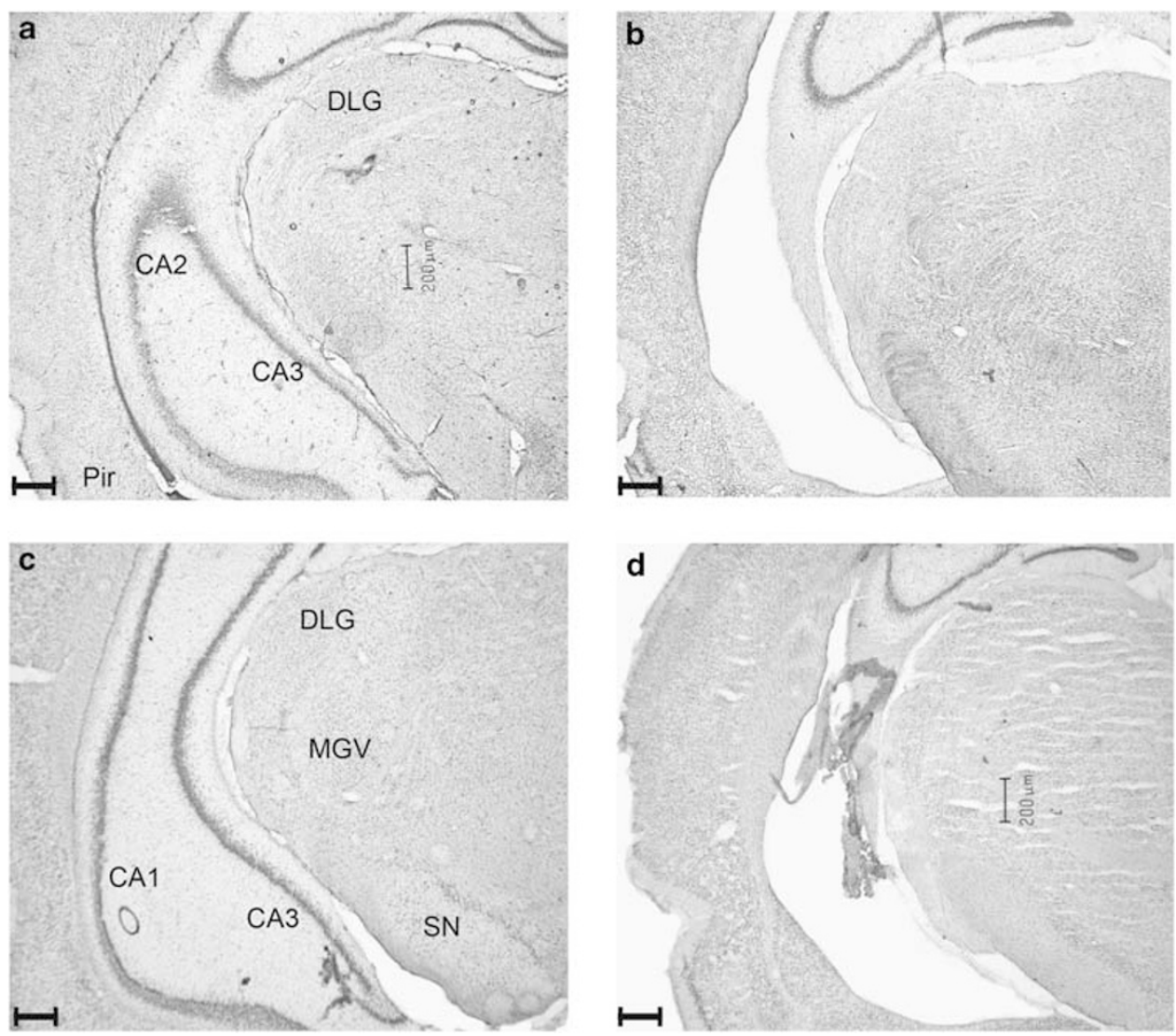

Figure I Representative coronal sections of the ventral hippocampal region of animals that received sham-lesions as adults (a) or neonates (c), or infusions of ibotenic acid as adults (b) or neonates (d; scales: $200 \mu \mathrm{m}$; all four sections are from Bregma AP levels -4.5 to $-4.8 \mathrm{~mm}$ ). At both ages, the lesions removed the ventral CA3 and CAI portions of the hippocampus and extended posteriorly to include the ventral dentate gyrus and subiculum. Damage to the adjacent piriform (Pir) and enthorinal cortex remained generally very limited. Additional landmark structures indicated on the sections from sham-lesioned brains are the dorsal lateral geniculate nucleus (DLG), the ventral part of the medial geniculate nucleus (MGV) as well as the substantia nigra (SN).

one-way repeated measures analysis of variance (ANOVA) for differences as a function of dialysis session or treatment group. In the absence of significant differences, subsequent drug effects were expressed as a percentage of the mean baseline for the treatment group. For each experiment, an overall ANOVA was conducted on ACh values using a two-way, within-subjects ANOVA with drug GROUP and TIME as within-subjects measures. In Experiment 2, an overall three-way ANOVA was initially conducted on within-subject factors of GROUP, TIME, and AGE followed by separate two-way ANOVAs at each age to show the source of certain interactions. In all ANOVAs, the HuynhFeldt correction was used to reduce Type 1 errors associated with repeated measures ANOVAs (Vasey and Thayer, 1987). When appropriate, a minimum number of post hoc comparisons were conducted using $t$-tests $(\alpha=0.05$ for all comparisons). All statistical tests were performed using SPSS for Windows (V15.0; SPSS Inc Chicago, IL).

\section{RESULTS}

\section{Ibotenic Acid-Induced Lesions of Ventral Hippocampus}

Figure 1 shows photomicrographs depicting representative coronal sections of the ventral hippocampal region in the brains of animals from each of the four lesion conditions; adult sham surgery (a), lesioned as adults (b), neonatal sham surgery (c), and neonatal lesions (d). At both ages, infusions of ibotenic acid led to comparable lesions within the ventral CA3 and CA1 portions of the hippocampus as well as the ventral dentate gyrus and subiculum. Infusions of vehicle in shams did not result in appreciable damage to the VH. Only rats with these anatomical profiles were included in the results.

\section{Experiment 1a: NMDA-Evoked ACh Release in nVHLX Tested as Adults}

The effects of NAC perfusion of NMDA on prefrontal ACh release in rats with sham or ibotenic acid (nVHLX) as neonates and tested as adults are illustrated in Figure 2. Mean $( \pm$ SEM) absolute basal ACh release across the four treatment groups was $5.07 \pm 0.27 \mathrm{fmol} / 15 \mu \mathrm{l}$. As basal ACh release did not differ among the groups $\left(\mathrm{F}_{3,42}=0.94\right.$, $P=0.43$ ), subsequent data were expressed as a percent change from each group's baseline. An overall analysis showed that ACh efflux varied as a function of lesion group, drug infused, and time (collection interval) $\left(\mathrm{F}_{10,130}=2.60\right.$, $P=0.006$ ). Subsequent analyses showed that the response to drug infusions differed significantly between sham and lesioned rats $\left(\mathrm{F}_{1,13}=17.37, P=0.001\right)$. In response to NMDA infusions, cortical ACh release in sham-lesioned rats markedly increased and remained elevated throughout the period of NMDA infusion and for one additional 


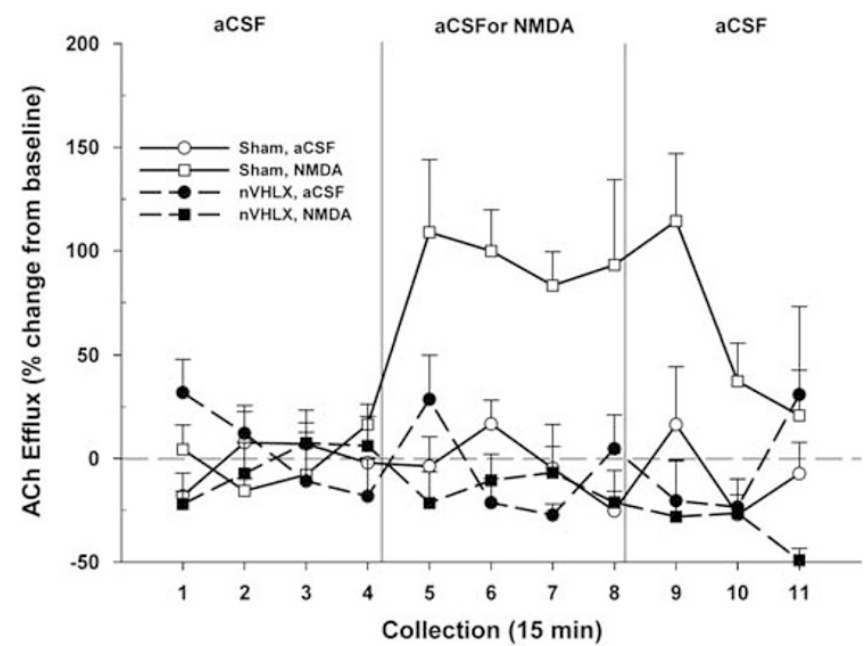

Figure 2 Mean $( \pm$ SEM) ACh efflux in the mPFC of sham-lesioned controls $(n=9)$ and $n V H L X$ rats $(n=6)$ receiving, in pseudo-randomized order, perfusions of vehicle (aCSF) or NMDA $(400 \mu \mathrm{M})$ into the NAC shell during two separate dialysis sessions as adults. After baseline collections $(\mathrm{I}-4)$, aCSF or NMDA was perfused for I h (5-8). After drug perfusion, aCSF was reperfused for $45 \mathrm{~min}(9-1 \mathrm{I})$ until the conclusion of the dialysis session. In sham animals, perfusion of NMDA produced a robust increase in cortical ACh efflux above that observed during aCSF perfusion. In $\mathrm{nVHLX}$ animals, however, perfusion of NMDA failed to increase cortical ACh efflux above baseline levels.

collection interval thereafter $\left(\mathrm{F}_{10,80}=3.91, P<0.001\right)$. Stimulated levels returned to baseline levels during the 10th collection $\left(t_{8}=-1.10, P=0.30\right)$. In striking contrast, in nVHLX rats, infusions of NMDA did not increase PFC ACh release, as indicated by the absence of a significant difference between the effects of perfusion of NMDA and $\operatorname{aCSF}\left(\mathrm{F}_{10,50}=1.94, P=0.120\right)$.

\section{Experiment 1b: NMDA-Evoked ACh Release in aVHLX Rats}

This experiment determined whether the ventral hippocampal lesion-induced attenuation of the NAC NMDAinduced increases in PFC ACh release depended on the age at which the $\mathrm{VH}$ was lesioned. The effects of intra-NAC perfusion of NMDA or the aCSF control on ACh efflux in PFC, in rats receiving hippocampal lesions as adults (aVHLX), are depicted in Figure 3. Mean ( \pm SEM) absolute basal ACh efflux across the four treatment groups was 5.78 $\pm 0.33 \mathrm{fmol} / 15 \mu \mathrm{l}$. As there were no significant differences among the groups in basal efflux $\left(F_{3,36}=0.94, P=0.43\right)$, subsequent data were expressed as a percent change from each group's baseline. In contrast to rats lesioned as neonates, NMDA-evoked ACh release in aVHLX animals was identical to that seen in sham-lesioned controls $\left(\mathrm{F}_{1,12}=0.01, P=0.94\right)$. Both lesioned and control rats exhibited comparable elevations of ACh during NMDA $\left(\mathrm{F}_{1,12}=0.10, P=0.76\right)$.

\section{Experiment 2: Emergence of Cholinergic Dysregulation Post Puberty}

This experiment determined whether the attenuated ability of accumbens NMDA receptor activity to stimulate prefrontal ACh release in nVHLX rats emerged gradually over

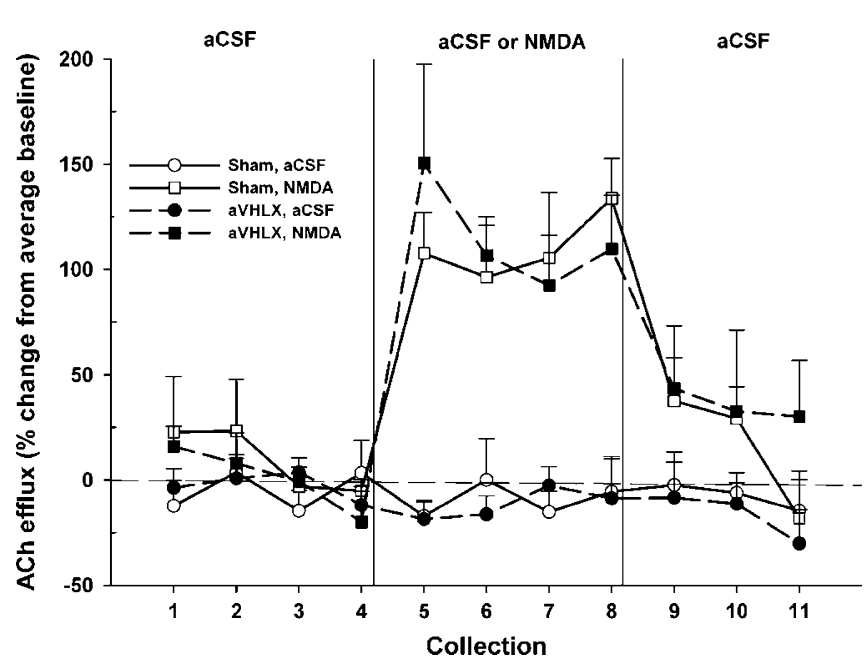

Figure 3 Mean $( \pm$ SEM) ACh efflux in the mPFC of sham-lesioned controls $(n=6)$ and aVHLX rats $(n=6)$ receiving, in pseudo-randomized order, perfusions of vehicle (aCSF) or NMDA $(250 \mu \mathrm{M})$ into the NAC shell during two separate dialysis sessions. After baseline collections (I-4), aCSF or NMDA was perfused for I h (5-8). After drug perfusion, aCSF was reperfused for $45 \mathrm{~min}(9-\mathrm{II})$ until the conclusion of the dialysis session. Perfusion of NMDA resulted in a sustained increase in cortical ACh efflux, above that observed during aCSF perfusion, in both sham and aVHLX animals. There was no effect of lesion on the NMDA-stimulated release.

the course of development. The same groups of nVHLX rats, and their sham controls, were tested for sensitivity to intra-accumbens NMDA infusions both prepuberty (days $30-38$ ) and post puberty (days 56-64) and the results are summarized in Figure 4. Furthermore, this experiment used a more demanding but also more stringent within-subject experimental design to reproduce the collective evidence obtained from Experiment 1. Both experimental approaches are necessary to exclude potential confounds that may be based on interactions between the lesions and repeated microdialysis sessions that are separated by an average of 26 days (Experiment 2) or on interactions between differential periods between the time of the lesion and cannulation surgery and the first insertion of a probe (Experiment 1).

Basal ACh levels in dialysates obtained prepuberty $v s$ post puberty did not differ among sham-lesioned and lesioned animals $\left(\mathrm{F}_{12,120}=1.86, P=0.07 ; 5.11 \pm 0.19 \mathrm{fmol} / 15 \mu \mathrm{l}\right)$. For clarity of presentation, the data for animals tested prepuberty (Figure 4, top) are presented separately from those obtained from these same animals tested post puberty (Figure 4, bottom). An omnibus ANOVA showed significant differences in ACh release as a function of lesion condition, NMDA/aCSF infusion, collection interval, and time of testing $\left(\mathrm{F}_{10,100}=2.67, P=0.01\right)$. More targeted comparisons indicated that intra-NAC perfusion of NMDA stimulated prefrontal ACh release in both sham-lesioned and lesioned rats when tested prepuberty (top panel; $F_{10,100}=4.31$, $P=0.002$ ). However, there was no overall difference between the two lesion conditions $\left(F_{1,10}=0.32, P=0.58\right)$. In contrast, the data depicted in the bottom panel resembled our earlier results (Figure 2) in nVHLX rats tested as adults. When tested post puberty, the response to NMDA perfusion differed markedly between sham controls and rats lesioned as neonates $\left(F_{1,10}=66.56, P<0.001\right)$. Finally, this developmental change in the ability of nVHLX rats to respond to 

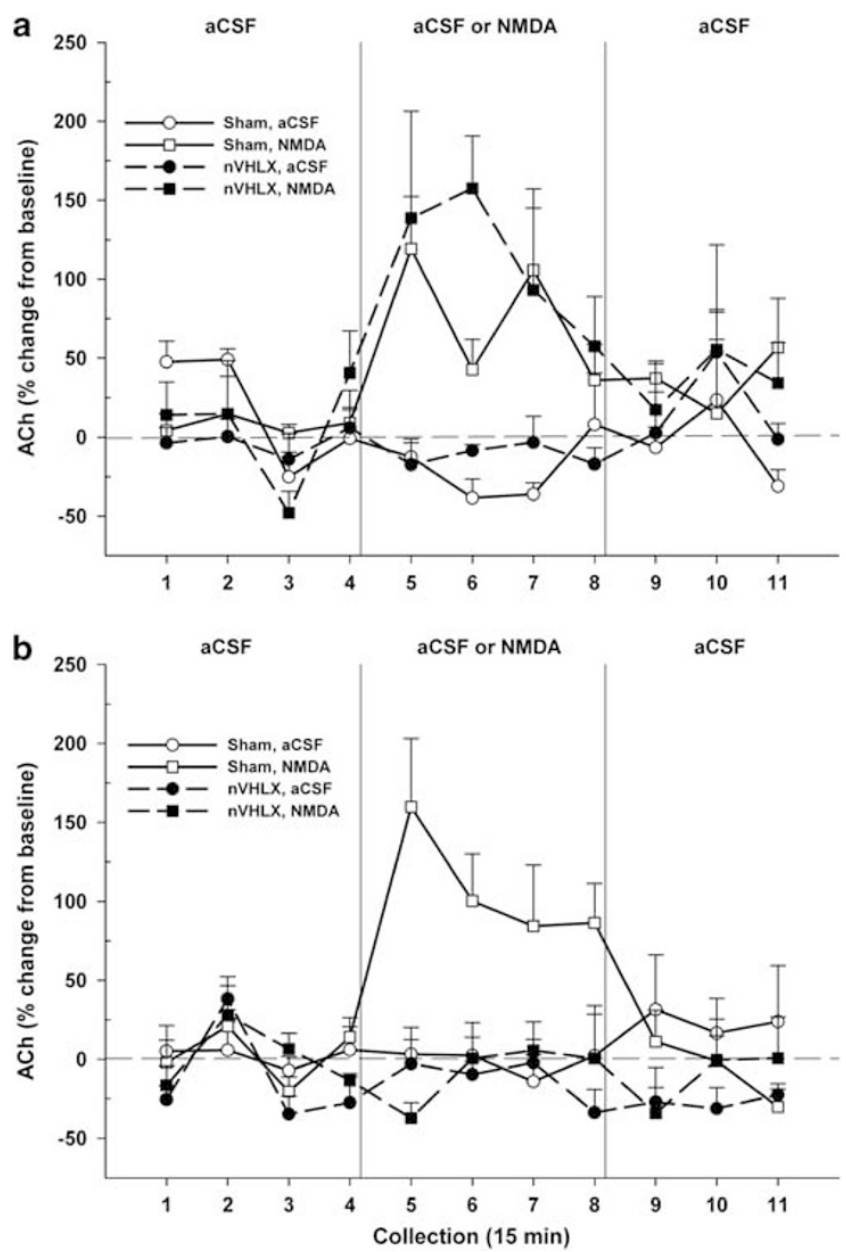

Figure 4 Mean $( \pm S E M)$ ACh efflux in the mPFC of sham-lesioned controls $(n=6)$ and $n V H L X$ rats $(n=6)$ tested at prepubertal (panel a; days 30-38) and again at postpubertal ages (panel b; days 56-64) for the effects of intra-NAC perfusions of aCSF or NMDA $(250 \mu \mathrm{M})$. When rats were tested prepuberty, both sham and $\mathrm{nVHLX}$ exhibited an NMDAstimulated release of ACh (collections 5-8). However, when these same rats were retested post puberty, the responsivity of $n V H L X$ rats to NMDA was lost and only sham-lesioned rats exhibited a drug-induced stimulation of ACh.

NMDA is highlighted by differences in a direct comparison between lesioned animals tested prepuberty and these same rats tested post puberty $\left(\mathrm{F}_{10,50}=2.88, P=0.01\right)$. The collective evidence from Experiments 1 and 2 conclusively indicates that the inability of intra-NAC NMDA to stimulate prefrontal ACh release in nVHLX animals emerges only after puberty.

Effects of systemic amphetamine. In light of the complete lack of response to NMDA in the NVHLX groups tested as adults (Figure 2) or post puberty (Figure 4, bottom), an additional microdialysis session was conducted in the postpubescent rats to determine whether the cortical cholinergic transmission of these nVHLX rats was sensitive to other stimulatory conditions and, in particular, to one that has been shown not to require NAC activity (Arnold et al, 2000). The ability of systemically administered amphetamine to stimulate prefrontal ACh release (Figure 5)

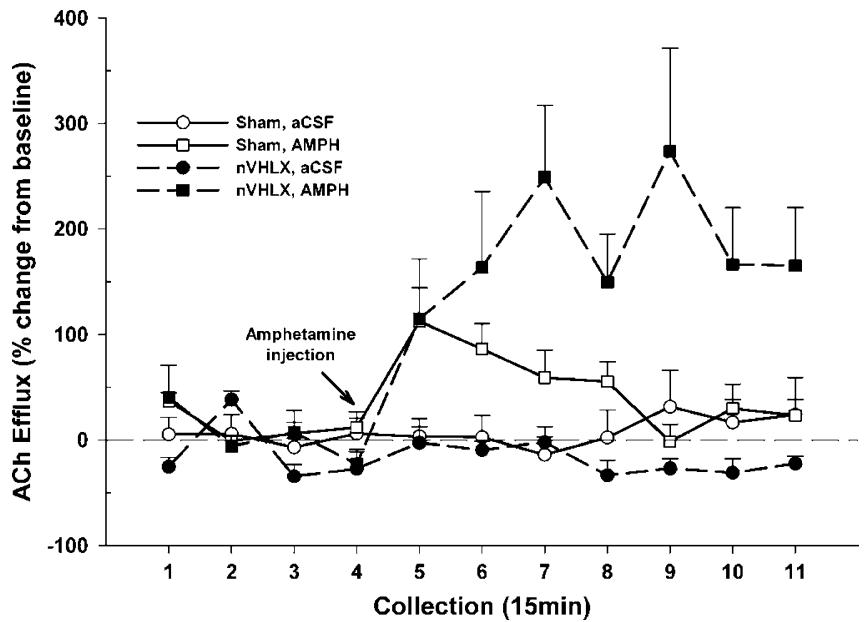

Figure 5 Mean $( \pm$ SEM) ACh efflux in the mPFC of shams $(n=6)$ or $n V H L X(n=6)$ rats receiving systemic injections of amphetamine (AMPH; $2 \mathrm{mg} / \mathrm{kg}$, i.p.) as adults. After baseline collections $(1-4)$, AMPH was injected. In contrast to the effects of NMDA (Figures 2 and 4b), administration of amphetamine resulted in robust increases in cortical ACh efflux in both sham and $\mathrm{nVHLX}$ groups, with lesioned animals exhibiting a potentiated release relative to that seen in control rats.

was a function of drug, lesion condition, and collection interval $\left(\mathrm{F}_{10,100}=3.47, P=0.009\right)$. Both sham controls and nVHLX rats responded to amphetamine with large and protracted increases in cortical ACh efflux, and, in contrast with the insensitivity to NMDA seen in lesioned rats (Figures 1, 3, and 4), nVHLX rats exhibited a greater response to amphetamine than did controls $\left(\mathrm{F}_{1,10}=13.98\right.$, $P=0.004)$. These results reject the possibility that as a result of the neonatal lesion, the adult cortical cholinergic input system fundamentally lacks the capacity to respond to stimulation.

\section{Experiment 3: Reversal by Semichronic Treatment with Clozapine}

The effects of semichronic treatment with saline (top panel) or clozapine (bottom panel) on the ability of intra-NAC NMDA to stimulate cortical cholinergic transmission in nVHLX animals are summarized in Figure 6. Mean ( \pm SEM) basal ACh release did not differ among sham-lesioned and lesioned rats after treatment with saline $(7.45 \pm 0.13 \mathrm{fmol} /$ $\left.15 \mu \mathrm{l} ; \mathrm{F}_{1,14}=2.09, P=0.17\right)$ or clozapine $(5.45 \pm 0.14 \mathrm{fmol} /$ $15 \mu \mathrm{l} ; \mathrm{F}_{1,14}=0.001 ; P=0.98$ ), although the overall differences in basal levels between the two pretreatment conditions did differ $\left(t_{30}=7.54, P<0.001\right)$. Although the elevated baselines after saline pretreatment were a bit unusual, they were judged not be of biological significance as the responses to NMDA infusions (see below) were very similar to those seen in non-pretreated rats (Experiments 1-2). Thus, subsequent analyses of ACh release were conducted and expressed as a percent change from these baselines. Neither did the semichronic pretreatment with saline affect the absence of NMDA-evoked ACh release in nVHLX rats nor the increase in ACh release seen in shamlesioned controls. ACh release in saline-treated animals (Figure 6, top) closely resembles the data obtained in Experiment 1a (Figure 2). An overall analysis showed a highly significant interaction between the effects of NMDA/aCSF, 

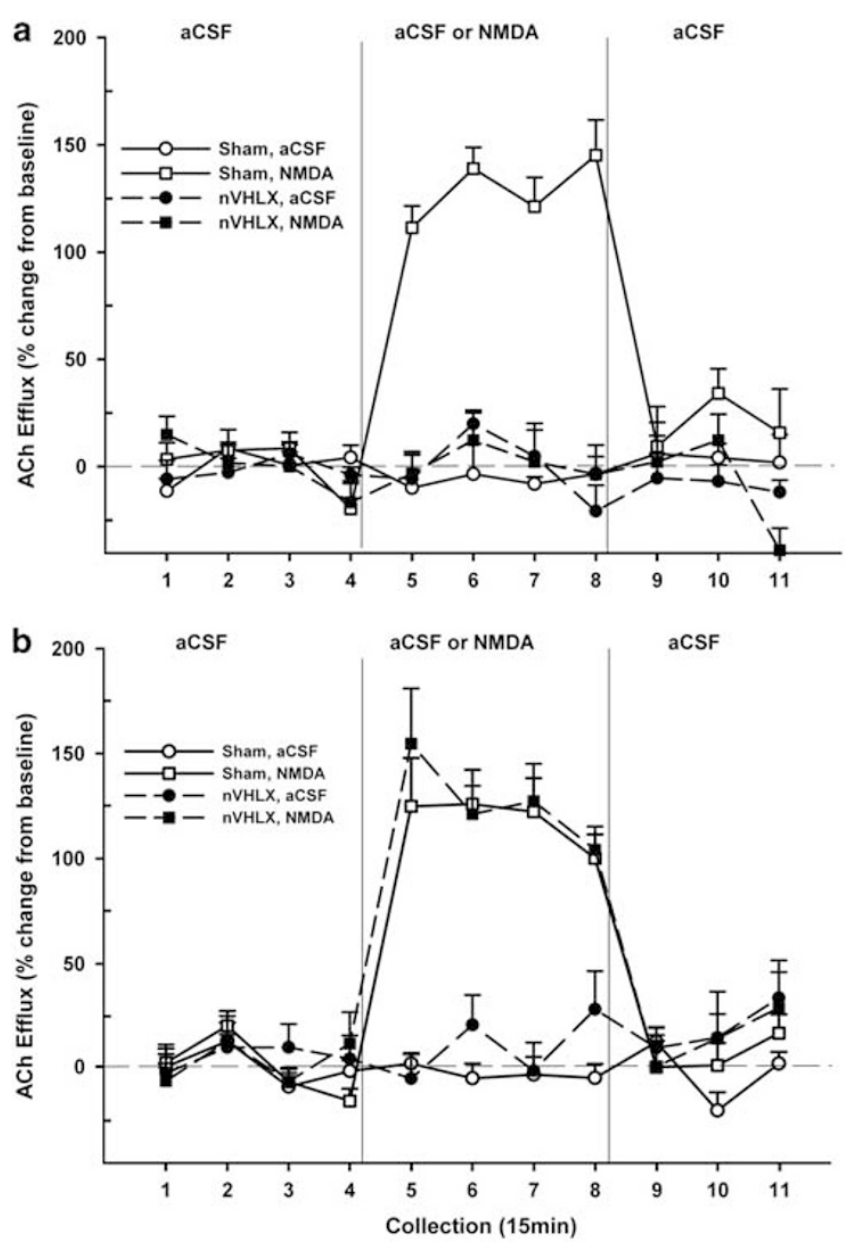

Figure 6 Mean $( \pm$ SEM) ACh efflux in the mPFC of sham $(n=8)$ or $n V H L X(n=8)$ rats after pretreatment (daily injections for 13 days) with either saline $(0.9 \%)$ or clozapine $(1.25 \mathrm{mg} / \mathrm{kg}$, i.p.) before microdialysis testing as adults. Each animal received, in pseudo-randomized order, perfusions of vehicle (aCSF) or NMDA $(250 \mu \mathrm{M})$ into the NAC shell during two dialysis sessions. The period for baseline infusions of aCSF and NMDA was the same as those reported in earlier experiments (Figures 2-4). In the control condition of saline pretreatment (panel a), the results of Experiment IA (Figure 2) were replicated. Namely, NMDA perfusion increased cortical ACh efflux in sham control animals whereas this effect was absent in $\mathrm{nVHLX}$ animals. After pretreatment with clozapine (panel b), $n V H L X$ animals exhibited a sham-control-like stimulation of $A C h$ release after intra-NAC perfusion of NMDA.

lesion condition, and collection interval $\left(\mathrm{F}_{10,140}=9.28\right.$, $P<0.001)$. Post hoc comparisons confirmed that intraNAC perfusion of NMDA produced the expected increase in ACh efflux, relative to aCSF, in sham-lesioned controls $\left(\mathrm{F}_{1,7}=231.21 ; P<0.001\right)$ but not in nVHLX rats $\left(\mathrm{F}_{1,7}=3.06\right.$; $P=0.82$ ).

In contrast, semichronic administration of clozapine resulted in a marked NMDA-evoked increase in PFC ACh release in nVHLX animals. The effect of clozapine was evident, statistically, by the absence of interactions between the effects of drug, lesion condition, and collection $\left(\mathrm{F}_{10,140}=0.74, P=0.68\right)$. Specifically, after clozapine pretreatment, the NMDA-evoked increases in ACh release in nVHLX rats $\left(\mathrm{F}_{1,7}=21.33 ; P=0.02\right)$ were indistinguishable from that seen in sham-lesioned rats $\left(F_{1,14}=0.32, P=0.58\right)$.

\section{DISCUSSION}

These experiments showed several novel findings regarding the impaired regulation of the cortical cholinergic system in rats sustaining lesions of the $\mathrm{VH}$ as neonates. First, the ability of NMDA receptor activation in the NAC to stimulate cortical ACh release, as seen in sham-lesioned controls, was completely lost in rats lesioned as neonates. Second, this lesion-induced deficit was age-dependent in that rats comparably lesioned as adults exhibited control-like elevations in cortical $\mathrm{ACh}$ release after intra-NAC perfusions of NMDA. Furthermore, the deficit in nVHLX rats emerged over the course of development as it appeared after puberty but was not present before puberty. Finally, semichronic treatment with a low dose of clozapine (for justification of dose see section Materials and Methods) in adulthood restored the ability of NMDA to evoke cortical ACh release in nVHLX rats. The discussion that follows addresses several issues related to the interpretation of these findings, including (a) the ability of intra-NAC NMDA perfusions to stimulate cortical cholinergic transmission, (b) the consequences of ventral hippocampal lesions during early development on the subsequent organization of the hippocampal-accumbens-basal forebrain-prefrontal cortical distributed system, and (c) the implications for the validity and usefulness of nVHLXs as an animal model of schizophrenia.

\section{Accumbens NMDA Receptors and Cortical Cholinergic Transmission}

Intra-accumbens perfusions of NMDA reliably evoked prefrontal ACh release in several groups of rats, including those that were sham-lesioned as neonates or adults, lesioned as adults, or lesioned as neonates and tested prepuberty. The ability of NMDA perfusions in NAC to stimulate cholinergic transmission in PFC has been shown earlier in intact rats (Brooks et al, 2007; Zmarowski et al, 2005, 2007), and the present evidence indicates that NMDA-evoked increases in release were generally unaffected in all groups except animals lesioned as neonates and tested post puberty.

The neuronal circuitry mediating the effects of NAC NMDA receptor stimulation to prefrontal cholinergic transmission is not completely understood. Glutamatergic inputs to the shell region of the NAC arise from multiple sources, including VH (subiculum; Groenewegen et al, 1987), amygdala (Yim and Mogenson, 1982), and PFC (O'Donnell and Grace, 1995; Gruber and O'Donnell, 2009). In the NAC, NMDA receptors are located, in high density, on medium spiny (MSN) projection neurons in NAC (Martin and Siggins, 2002). These projection neurons may modulate cortical ACh release by directly regulating basal forebrain activity. A high proportion of basal forebrain neurons, many of which are cholinergic (Henny and Jones, 2008), are innervated by GABAergic projections, most likely from the NAC (Ingham et al, 1988; Zaborszky and Cullinan 1992). Moreover, accumbens projections may contact basal forebrain GABAergic corticopetal neurons (Henny and Jones, 2008) and these inputs, through their contacts with cortical GABAergic interneurons (Henny and Jones, 2008; Zaborszky et al, 1999), have the potential to regulate cortical ACh release through local mechanisms. Finally, the ability 
of NAC efferents to modulate cortical cholinergic transmission may involve more indirect mechanisms such as projections back to VTA (Usuda et al, 1998) and then to basal forebrain (Gaykema and Zaborszky 1996), or projections from VTA directly to PFC (Lewis and O'Donnell, 2000) for local regulation of ACh release. Additional research will be required to identify the contributions of these various circuits.

Several observations suggest that the loss of NMDAevoked ACh release in NVHLX animals tested post puberty was not secondary to NMDA-induced damage to the NAC projection neurons or the basal forebrain cortical cholinergic system. First, three of the four treatment groups in this study (shams at both age groups and aVHLX rats) remained responsive to intra-NAC perfusions. Second, even nVHLX rats exhibited a control-like response to NMDA when tested prepuberty. Third, nVHLX rats that had not responded to NMDA as adults exhibited a normal response after semichronic treatment with clozapine. Finally, nVHLX rats that were unresponsive to NMDA displayed elevated cortical ACh release after systemic amphetamine.

\section{Mechanistic Considerations}

The effects of ibotenic acid-induced lesions of the $\mathrm{VH}$ on cortical cholinergic transmission depended markedly on the age at which the lesion was sustained and the age at the time of testing. This lesion, at this sensitive period of development, disrupts the maturation of the NAC-BF-PFC circuit that is shown by the effects of stimulation of NAC NMDA receptors post puberty. In adult rats, the activity of ventral hippocampal projections, in interaction with dopaminergic inputs from VTA, regulate the accumbens' responsivity to prefrontal excitatory inputs (Grace, 2000; O'Donnell and Grace, 1995). In addition, VH projections constitute a major source of excitatory input to PFC (Lewis and O'Donnell, 2000). The collective evidence on the age-dependent effects of lesions to the $\mathrm{VH}$ indicates anatomical, molecular, and neurochemical alterations consistent with the theory that neonatal, but not adult, lesions induce a reorganization of this circuit, and that the maladaptive consequences of this plasticity functionally express themselves around the time of puberty. For example, the length and branching of basilar dendrites, as well as their density, were reduced in PFC and NAC of nVHLX, but not aVHLX, rats (Flores et al, 2005). These anatomical changes are accompanied by an increased expression of NR1 mRNA in PFC that is seen post puberty but not prepuberty (El-Rawas et al, 2009). Electrophysiological recordings of NAC modulation of prefrontal activity also show maturationally dependent impairments in nVHLX rats. VTA-evoked depolarizations are accompanied by a high frequency of NAC (Brady and O'Donnell, 2004) or PFC (O’Donnell et al, 2002) spike firing in postpubescent rats (but not prepubsecent rats) lesioned as neonates, but a marked suppression of spike firing in controls and rats lesioned as adults. The enhanced activation of PFC neurons may be secondary to a puberty-dependent loss of D2 modulation of prefrontal interneurons (Tseng et al, 2008) and might be expected to contribute to 'noisy' cortical information processing. The heightened responsivity of NAC neurons after the lesion was normalized by subchronic administration of haloperidol (Goto and O'Donnell, 2002) or lesions of the PFC (Goto and O'Donnell, 2004).

An earlier study identified deficits in the regulation of cortical cholinergic transmission after $\mathrm{nVH}$ lesions that, as in this study and those referenced above, became evident only during or after puberty (LaPlante et al, 2004). Specifically, systemic administration of a D1 agonist stimulated prefrontal $\mathrm{ACh}$ release to a greater degree in lesioned than in control rats. Moreover, local perfusion of a D1 agonist did not affect ACh release in the PFC of controls but stimulated release in rats lesioned as neonates.

Taken together, numerous plastic changes within the NAC-BF-PFC circuit, ranging from structural modification of dendritic trees to variations in the expression of receptors, result from $\mathrm{nVH}$ lesions in interaction with brain maturation. In conceptual terms, such lesions serve to model maturational abnormalities in this circuit, and the effects of NMDA infusions into the NAC show these abnormalities.

\section{Causal Relationships Between Dysregulated Cholinergic Neurotransmission and Cognitive, Specifically Attentional Impairments}

The present results indicate that an abnormally regulated cortical cholinergic input system represents a hallmark of this animal model of schizophrenia. The significance of this finding concerns the overarching hypothesis that a dysregulated cholinergic system contributes to, or is even primarily responsible for, the attentional impairments that result from nVHLX. First, as adults, nVHLX animals were found to exhibit attentional impairments in experiments assessing attentional set shifting (Marquis et al, 2008) and performance in the five-choice serial reaction time task (Le Pen et al, 2003). Furthermore, the repeatedly demonstrated impairments in sensory gating (Lipska et al, 1995; Le Pen et al, 2000; Rueter et al, 2004) likewise may reflect a fundamental disruption in cognition-associated input processing caused by nVHLX.

Second, a substantial body of evidence indicates that an abnormally regulated cortical cholinergic input system causes impairments in attention. Removal of cholinergic inputs to the cortex causes persistent impairments in attentional performance, assessed by a range of tasks (eg, McGaughy et al, 1996, 2002). Our experiments concerning an animal model of schizophrenia that results from exposure to an escalating-dose regimen of amphetamine generated additional, relevant evidence. We observed that disruption of attentional performance in these animals was associated with a failure of the prefrontal cholinergic input system to respond to task. Prefrontal ACh release remained at baseline throughout the test session and performance remained close to chance level (Kozak et al, 2007). Importantly, the 'freezing' of ACh release at baseline levels was noticeable before task onset, allowing a causal interpretation: the failure of the cholinergic system to depart from baseline activity levels caused the impairment, as opposed to representing merely a correlate of disrupted performance. The present evidence likewise would predict that, in nVHLX animals, the attentional task-induced recruitment of prefrontal-mesolimbic-basal forebrain circuits 
(Sarter et al, 2006) is disrupted and that performanceassociated increase in prefrontal $\mathrm{ACh}$ release is attenuated.

Although it will be important to show in future experiments that attentional task-performing nVHLX animals exhibit attenuated levels of ACh release, causal relationships are more difficult to derive from such studies and may be based on evidence indicating treatment-induced covariation of $\mathrm{ACh}$ release and performance. We know already that, in intact animals, infusions of NMDA into the NAC benefits attentional performance, specifically in interaction with performance challenges that are thought to activate top-down mechanisms, including mesolimbicbasal forebrain circuitry (St. Peters et al, 2009). In nVHLX animals, such infusions would be expected to normalize the task performance-associated increases in cholinergic neurotransmission. Unfortunately, experiments necessitating the measurement of ACh release in task-performing animals and in response to bilateral intracranial infusions are extremely challenging.

Taken together, there is growing evidence indicating that nVHLX causes impairments in attention and that abnormally regulated activity of cortical cholinergic inputs causes impairments in attention. Therefore, the unresponsive cholinergic system in adult nVHLX animals is likely to be primarily responsible for the attentional impairments that were shown in these animals.

\section{Implications for the Validity and Usefulness of nVHLX as an Animal Model for Schizophrenia}

Increases in prefrontal cholinergic activity have been suggested to contribute to the recruitment of the 'anterior attention system' and therefore to the activation of topdown mechanisms that act to maintain and recover attentional performance under challenging conditions (see Introduction). NMDA perfusions into the NAC are thought to mimic, in part, the recruitment of mesolimbic-BFCS interactions that are required to optimize attentional mechanisms in response to performance challenges. As impairments of the attentional abilities of schizophrenic patients are particularly severe when challenged (for review see Sarter et al, 2009), the loss of NMDA-mediated activation of the prefrontal cholinergic system in nVHLX animals is interpreted as reflecting a loss in the ability to recruit, top-down, the mechanisms that normally support attentional performance and performance recovery (see above).

Consistent with the schizophrenia phenotype, nVHLX animals exhibit a range of cognitive deficits in the attentional and other cognitive domains (see above, see also Chambers et al, 1996). As our research focuses on the established role of cholinergic neurotransmission for attention, the present results specifically are considered to indicate a neuronal mechanism that might be responsible for the vulnerability of schizophrenic patients to challenges to attentional capacities. As discussed elsewhere (Sarter et al, 2005b, 2009) such vulnerability may not merely represent one among many cognitive problems of schizophrenic patients, but may instrumentally contribute to the severity of a wide range of cognitive impairments and thus have been proposed to represent a primary target for treatment developments (Nuechterlein et al, 2009; Young et al, 2009).

Finally, the finding that low-dose treatment with clozapine reversed the lesion-induced deficit in NMDA-mediated cortical ACh release contributes to the predictive validity of this particular neurochemical assay within the nVHLX model. The finding also supports further the usefulness of low-dose antipsychotic treatments to determine the predictive validity of animal models in the absence of more efficacious cognition enhancers (Martinez and Sarter, 2008). Importantly, this normalization of NAC-BF-PFC function was not seen after the acute administration of either clozapine or haloperidol (Brooks, unpublished observations). The mechanisms underlying the ability of clozapine to restore cholinergic transmission have not been resolved. One rather straight-forward possibility is that the neonatal lesion results in elevated levels of D2-mediated neurotransmission in NAC. We have shown earlier, in intact rats, that intra-NAC perfusions of the D2-like agonist quinpirole blocks the ability of concurrent NMDA administration to stimulate prefrontal ACh release (Brooks et al, 2007), suggesting the excessive D2-like receptor activity in NAC can dampen the NMDA modulation of prefrontal ACh release. However, we have also observed abnormalities in the generation of cholinergic activity based on local prefrontal circuitry (Wescott et al, 2009), suggesting a possible role of disrupted prefrontal circuitry (Tseng et al, 2008) in the failure of NAC stimulation to activate PFC cholinergic activity. Finally, it seems likely, of course, that the functional consequences of an abnormally organized PFC are magnified by the inability of the cholinergic input to recruit PFC circuitry.

In summary, the results reported here show that damage to the $\mathrm{VH}$ during a critical period of early development interacts with maturational variables at or around the time of puberty to produce a permanent dysregulation in a circuit involving the PFC, the NAC, and basal forebrain cholinergic projections to the PFC. This abnormal limbic-cortical interaction is likely to contribute significantly to the attentional deficits evident in schizophrenia. These results, including the ability of low-dose clozapine to restore aspects of the functionality of this circuit, suggest that this animal model may be useful for studying the neuronal mechanisms mediating the cognitive impairments of schizophrenia and the efficacy of putative treatments for these impairments.

\section{ACKNOWLEDGEMENTS}

The authors' research was supported by research grants from the National Institute of Health (MH057436 to JPB and MS; MH080426 and MH 080332 to MS).

\section{DISCLOSURE}

The authors have nothing to disclose nor are there conflicts of interest in matters associated with the experiments presented in this manuscript. 


\section{REFERENCES}

Arnold HM, Nelson CL, Neigh GH, Sarter M, Bruno JP (2000). Systemic and intra-accumbens administration of amphetamine differentially affects cortical acetylcholine release. Neuroscience 96: 675-685.

Barch DM, Carter CS, Arnsten A, Buchanan RW, Cohen JD, Geyer $M$ et al. (2009). Selecting paradigms from cognitive neuroscience for translation into use in clinical trials: proceedings of the third CNTRICS meeting. Schizophr Bull 35: 109-114.

Bhardwaj SK, Beaudry G, Quirion R, Levesque D, Srivastava LK (2003). Neonatal ventral hippocampus lesion leads to reductions in nerve growth factor inducible-B mRNA in the prefrontal cortex and increased amphetamine response in the nucleus accumbens and dorsal striatum. Neuroscience 122: 669-676.

Brady AM, O'Donnell P (2004). Dopaminergic modulation of prefrontal cortical input to nucleus accumbens neurons in vivo. J Neurosci 24: 1040-1049.

Braff DL, Light GA (2004). Preattentional and attentional cognitive deficits as targets for treating schizophrenia. Psychopharmacology (Berl) 174: 75-85.

Brooks JM, Sarter M, Bruno JP (2007). D2-like receptors in nucleus accumbens negatively modulate acetylcholine release in prefrontal cortex. Neuropharmacology 53: 455-463.

Chambers RA, Moore J, McEvoy JP, Levin ED (1996). Cognitive effects of neonatal hippocampal lesions in a rat model of schizophrenia. Neuropsychopharmacology 15: 587-594.

El-Rawas R, Saadé NE, Thiriet N, Atweh S, Jaber M, Al-Amin HA (2009). Developmental changes in the mRNA expression of neuropeptides and dopamine and glutamate receptors in neonates and adult rats after hippocampal lesion. Schizophr Res [E-pub ahead of print].

Flores G, Alquicer G, Silva-Gómez AB, Zaldivar G, Stewart J, Quirion $\mathrm{R}$ et al. (2005). Alterations in dendritic morphology of prefrontal cortical and nucleus accumbens neurons in postpubertal rats after neonatal excitotoxic lesions of the ventral hippocampus. Neuroscience 133: 463-470.

Gaykema RP, Zaborszky L (1996). Direct catecholaminergiccholinergic interactions in the basal forebrain II. Substantia nigra-ventral tegmental area projections to cholinergic neurons. J Comp Neurol 374: 555-577.

Goto Y, O’Donnell P (2002). Delayed mesolimbic system alteration in a developmental animal model of schizophrenia. J Neurosci 22: 9070-9077.

Goto Y, O’Donnell P (2004). Prefrontal lesion reverses abnormal mesoaccumbens response in an animal model of schizophrenia. Biol Psychiatry 55: 172-176.

Grace AA (2000). Gating of information flow within the limbic system and the pathophysiology of schizophrenia. Brain Res Rev 31: $330-341$.

Groenewegen HJ, Vermeulenvanderzee E, Kortschot AT, Witter MP (1987). Organization of the projections from the subiculum to the ventral striatum in the rat - a study using anterograde transport of phaseolus-vulgaris leukoagglutinin. Neuroscience 23: $103-120$.

Gruber AJ, O’Donnell P (2009). Bursting activation of prefrontal cortex drives sustained up states in nucleus accumbens spiny neurons in vivo. Synapse 63: 173-180.

Hagan JJ, Jones DN (2005). Predicting drug efficacy for cognitive deficits in schizophrenia. Schizophr Bull 31: 830-853.

Henny P, Jones BE (2008). Projections from basal forebrain to prefrontal cortex comprise cholinergic, GABAergic and glutamatergic inputs to pyramidal cells or interneurons. Eur $J$ Neurosci 27: 654-670.

Himmelheber AM, Sarter M, Bruno JP (2000). Increases in cortical acetylcholine release during sustained attention performance in rats. Cogn Brain Res 9: 313-325.
Huang T, Yang L, Gitzen J, Kissinger PT, Vreeke M, Heller A (1995). Detection of basal acetylcholine in rat brain microdialysates. J Chromatogr 670: 323-327.

Hyde TM, Crook JM (2001). Cholinergic systems and schizophrenia: primary pathology or epiphenomena? J Chem Neuroanat 22: 53-63.

Ichikawa J, Dai J, O'Laughlin IA, Fowler WL, Meltzer HY (2002). Atypical, but not typical, antipsychotic drugs increase cortical acetylcholine release without an effect in the nucleus accumbens or striatum. Neuropsychopharmacology 26: 325-339.

Ingham CA, Bolam JP, Smith AD (1988). GABA-immunoreactive synaptic boutons in the rat basal forebrain: comparison of neurons that project to the neocortex with pallidosubthalamic neurons. J Comp Neurol 273: 263-282.

Kapur S, VanderSpek SC, Brownlee BA, Nobrega JN (2003). Antipsychotic dosing in preclinical models is often unrepresentative of the clinical condition: a suggested solution based on in vivo occupancy. J Pharmacol Exp Ther 305: 625-631.

Kerns JG, Neuchterlein KH, Braver TS, Barch DM (2008). Executive functioning component mechanisms and schizophrenia. Biol Psychiatry 64: 26-33.

Kozak R, Martinez V, Young D, Brown H, Bruno JP, Sarter M (2007). Toward a neuro-cognitive animal model of the cognitive symptoms of schizophrenia: disruption of cortical cholinergic neurotransmission following repeated amphetamine exposure in attentional task-performing, but not non-performing, rats. Neuropsychopharmacology 32: 2074-2086.

Kozak R, Bruno JP, Sarter M (2006). Augmented prefrontal acetylcholine release during challeneged attentional performance. Cereb Cortex 16: 9-17.

Kozak R, Martinez V, Young D, Brown H, Bruno JP, Sarter M (2007). Toward a neuro- cognitive animal model of the cognitive symptoms of schizophrenia: disruption of cortical cholinergic neurotransmission following repeated amphetamine exposure in attentional task-performing, but not non-performing, rats. Neuropsychopharmacology 32: 2074-2086.

LaPlante F, Srivastava LK, Quirion R (2004). Alterations in dopaminergic modulation of prefrontal cortical acetylcholine release in post-pubertal rats with neonatal ventral hippocampal lesions. J Neurochem 89: 314-323.

Le Pen G, Grottick AJ, Higgins GA, Moreau JL (2003). Phencyclidine exacerbates attentional deficits in a neurodevelopmental rat model of schizophrenia. Neuropsychopharmacology 28: 1799-1809.

Le Pen G, Grottick AJ, Higgins GA, Martin JR, Jenck F, Moreau JL (2000). Spatial and associative learning deficits induced by neonatal excitotoxic hippocampal damage in rats: further evaluation of an animal model of schizophrenia. Behav Pharmacol 11: 257-268.

Lewis BL, O’Donnell P (2000). Ventral tegmental area afferents to the prefrontal cortex maintain membrane potential 'up' states in pyramidal neurons via $\mathrm{D}(1)$ dopamine receptors. Cereb Cortex 10: $1168-1175$.

Li Z, Huang M, Ichikawa J, Dai J, Meltzer HY (2005). Ndesmethylclozapine, a major metabolite of clozapine, increases cortical acetylcholine and dopamine release in vivo via stimulation of M1 muscarinic receptors. Neuropsychopharmacology 30: 1986-1995.

Lipska BK, Jaskiw GE, Weinberger DR (1993). Postpubertal emergence of hyperresponsiveness to stress and amphetamine after neonatal excitotoxic hippocampal damage: a potential animal model of schizophrenia. Neuropsychopharmacology 9: 67-75.

Lipska BK, Swerdlow NR, Geyer MA, Jaskiw GE, Braff DL, Weinberger DR. (1995). Neonatal excitotoxic hippocampal damage in rats causes post-pubertal changes in prepulse 
inhibition of startle and its disruption by apomorphine. Psychopharmacology 122: 35-43.

Lipska BK, Lerman DN, Khaing ZZ, Weickert CS, Weinberger DR (2003). Gene expression in dopamine and GABA systems in an animal model of schizophrenia: effects of antipsychotic drugs. Eur J Neurosci 18: 391-402.

Marquis JP, Goulet S, Dore FY (2008). Neonatal ventral hippocampus lesions disrupt extra-dimensional shift and alter dendritic spine density in the medial prefrontal cortex of juvenile rats. Neurobiol Learn Mem 90: 339-346.

Martin G, Siggins GR (2002). Electrophysiological evidence for expression of glycine receptors in freshly isolated neurons from nucleus accumbens. J Pharmacol Exp Ther 302: 1135-1145.

Martinez V, Sarter M (2008). Detection of the moderately beneficial cognitive effects of low-dose treatment with haloperidol or clozapine in an animal model of the attentional impairments of schizophrenia. Neuropsychopharmacology 33: 2635-2647.

McGaughy J, Dalley JW, Morison CH, Everitt BJ, Robbins TW (2002). Selective behavioral and neurochemical effects of cholinergic lesions produced by intrabasalis infusions of 192 IgG-saporin on attentional performance in a five-choice serial reaction time task. J Neurosci 22: 1905-1913.

McGaughy J, Kaiser T, Sarter M (1996). Behavioral vigilance following infusions of 192 IgG-saporin into the basal forebrain: selectivity of the behavioral impairment and relation to cortical AChE-positive fiber density. Behav Neurosci 110: 247-265.

Mishara AL, Goldberg TE (2004). A meta-analysis and critical review of the effects of conventional neuroleptic treatment on cognition in schizophrenia: opening a closed book. Biol Psychiatry 55: 1013-1022.

Nuechterlein KH, Barch DM, Gold JM, Goldberg TE, Green MF, Heaton RK (2004). Identification of separable cognitive factors in schizophrenia. Schizophr Res 72: 29-39.

Nuechterlein KH, Dawson ME (1984). Information processing and attentional functioning in the developmental course of schizophrenic disorders. Schizophr Bull 10: 160-203.

Nuechterlein KH, Luck SJ, Lustig C, Sarter M (2009). CNTRICS final task selection: control of attention. Schizophr Bull 35: 182-196.

O’Donnell P, Grace AA (1995). Synaptic interactions among excitatory afferents to nucleus accumbens neurons: hippocampal gating of prefrontal cortical input. J Neurosci 15: 3622-3639.

O'Donnell P, Lewis BL, Weinberger DR, Lipska BK (2002). Neonatal hippocampal damage alters electrophysiological properties of prefrontal cortical neurons in adult rats. Cereb Cortex 12: 975-982.

Potter PE, Meek JL, Neff NH (1983). Acetylcholine and choline in neuronal tissue measured by HPLC with electrochemical detection. J Neurochem 41: 188-194.

Raedler TJ, Knable MB, Jones DW, Urbina RA, Gorey JG, Lee KS et al. (2003). In vivo determination of muscarinic acetylcholine receptor availability in schizophrenia. Am J Psychiatry 160: 118-127.

Rueter LE, Ballard ME, Gallagher KB, Basso AM, Curzon P, Kohlhaas KL (2004). Chronic low dose risperidone and clozapine alleviate positive but not negative symptoms in the rat neonatal ventral hippocampal lesion model of schizophrenia. Psychopharmacology (Berl) 176: 312-319.

Sarter M, Gehring WJ, Kozak R (2006). More attention must be paid: the neurobiology of attentional effort. Brain Res Rev 51: 145-160.
Sarter M, Hasselmo ME, Bruno JP, Givens B (2005a). Unraveling the attentional functions of cortical cholinergic inputs: interactions between signal-driven and cognitive modulation of signal detection. Brain Res Rev 48: 98-111.

Sarter M, Martinez V, Kozak R (2009). A neurocognitive animal model dissociating between acute illness and remission periods of schizophrenia. Psychopharmacology (Berl) 202: 237-258.

Sarter M, Nelson CL, Bruno JP (2005b). Cortical cholinergic transmission and cortical information processing in schizophrenia. Schizophr Bull 31: 117-138.

St Peters M, Bruno J.P, Sarter M (2009). Accumbens NMDA Receptor Stimulation Enhances Attentional Performance as a Function of Demands on Top-Down Control. Society for Neuroscience Annual Meeting: Chicago, IL.

Tseng KY, Amin F, Lewis BL, O'Donnell P (2006). Altered prefrontal cortical metabolic response to mesocortical activation in adult animals with a neonatal ventral hippocampal lesion. Biol Psychiatry 60: 585-590.

Tseng KY, Lewis BL, Hashimoto T, Sesack SR, Kloc M, Lewis DA et al. (2008). A neonatal ventral hippocampal lesion causes functional deficits in adult prefrontal cortical interneurons. J Neurosci 28: 12691-12699.

Tseng KY, Lewis BL, Lipska BK, O’Donnell P (2007). Post-pubertal disruption of medial prefrontal cortical dopamine-glutamate interactions in a developmental animal model of schizophrenia. Biol Psychiatry 62: 730-738.

Usuda I, Tanaka K, Chiba T (1998). Efferent projections of the nucleus accumbens in the rat with special reference to subdivision of the nucleus: biotinylated dextran amine study. Brain Res 797: 73-93.

Vasey MW, Thayer JF (1987). The continuing problem of false positives in repeated measures ANOVA in psychophysiology-a multivariate solution. Psychophysiology 24: 479-489.

Wescott S, Gritton H, Parikh V, Bruno JP, Sarter M (2009). Nicotine-evoked recruitment of prefrontal, signal detectionmediating mechanisms, are abolished in the neonatal ventral hippocampal lesion model of schizophrenia. Society for Neuroscience Annual Meeting: Chicago, IL.

Yim CY, Mogenson GJ (1982). Response of nucleus accumbens neurons to amygdala stimulation and its modification by dopamine. Brain Res 239: 401-415.

Young JW, Powell SB, Risbrough V, Marston HM, Geyer MA (2009). Using the MATRICS to guide development of a preclinical cognitive test battery for research in schizophrenia. Pharmacol Ther 122: 150-202.

Zaborszky L, Cullinan WE (1992). Projections from the nucleus accumbens to cholinergic neurons of the ventral pallidum: a correlated light and electron microscopic double-immunolabeling study in rat. Brain Res 570: 92-101.

Zaborszky L, Pang K, Somogyi J, Nadasdy Z, Kallo I (1999). The basal forebrain corticopetal system revisited. Ann N Y Acad Sci 877: 339-367.

Zmarowski A, Sarter M, Bruno JP (2005). NMDA and dopamine interactions in the nucleus accumbens modulate cortical acetylcholine release. Eur J Neurosci 22: 1731-1740.

Zmarowski A, Sarter M, Bruno JP (2007). Glutamate receptors in nucleus accumbens mediate regionally selective increases in cortical acetylcholine release. Synapse 61: 115-123. 